Corrigendum

\title{
Corrigendum to "Verification of the Dose Reduction Effect via Diluted Injection in Dual-Energy Computed Tomography Using a Human Blood Flow Phantom"
}

\author{
Hironobu Tomita ${ }^{10}{ }^{1,2}$ and Koichi Shibata ${ }^{1}$ \\ ${ }^{1}$ Graduate School of Health Science, Suzuka University of Medical Science, 1001-1, Kishiokacho, Suzuka, Mie 510-0293, Japan \\ ${ }^{2}$ Department of Radiology, Saiseikai Kawaguchi General Hospital, 5-11-5, Nishikawaguchi, Kawaguchi, Saitama 332-0021, Japan \\ Correspondence should be addressed to Hironobu Tomita; ae861600@js7.so-net.ne.jp
}

Received 28 May 2019; Accepted 10 June 2019; Published 19 June 2019

Copyright @ 2019 Hironobu Tomita and Koichi Shibata. This is an open access article distributed under the Creative Commons Attribution License, which permits unrestricted use, distribution, and reproduction in any medium, provided the original work is properly cited.

In the article titled "Verification of the Dose Reduction Effect via Diluted Injection in Dual-Energy Computed Tomography Using a Human Blood Flow Phantom" [1], the first affiliation was written incorrectly. The corrected authors' list and affiliations are shown above.

\section{References}

[1] H. Tomita and K. Shibata, "Verification of the dose reduction effect via diluted injection in dual-energy computed tomography using a human blood flow phantom," Radiology Research and Practice, vol. 2019, Article ID 3512126, 9 pages, 2019. 


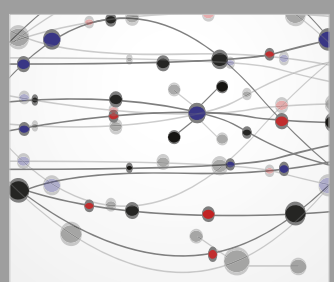

The Scientific World Journal
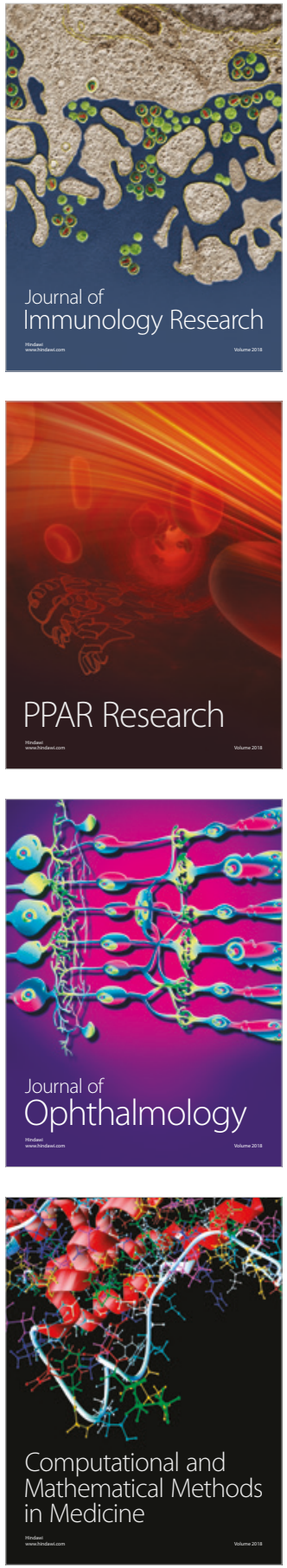

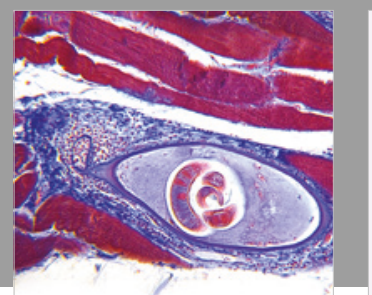

Gastroenterology Research and Practice

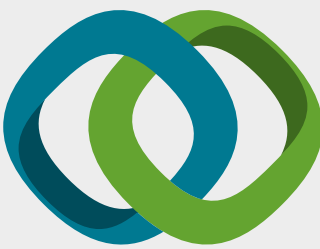

\section{Hindawi}

Submit your manuscripts at

www.hindawi.com
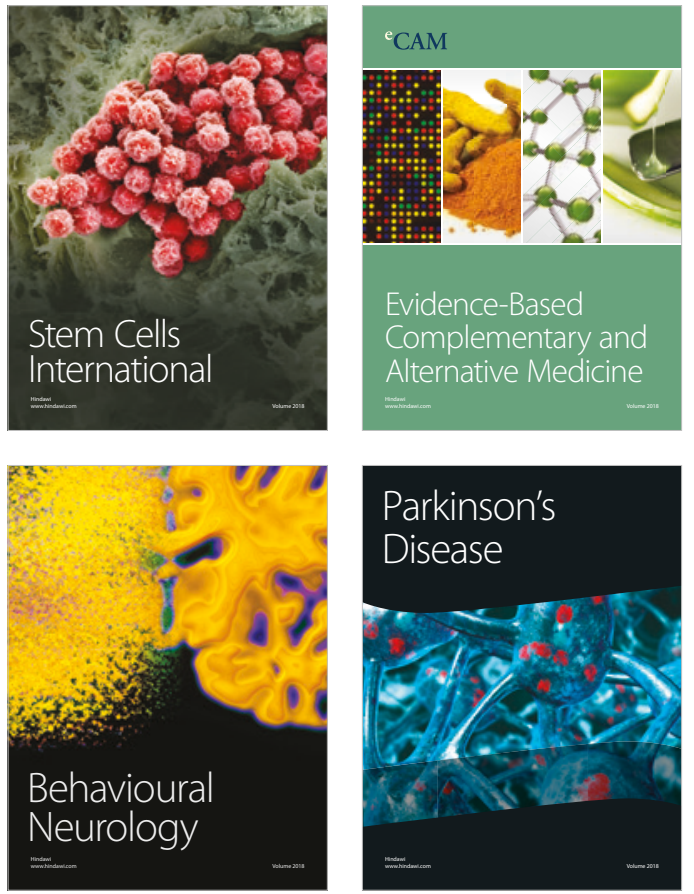

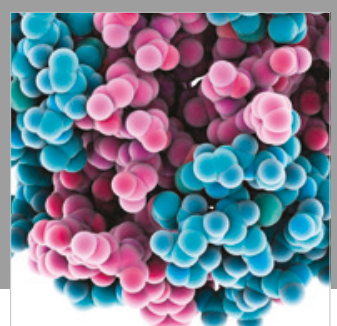

ournal of

Diabetes Research

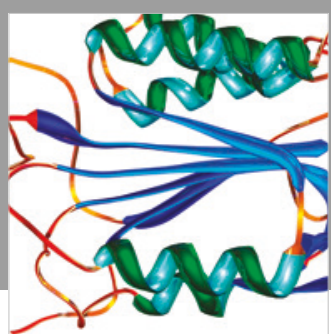

Disease Markers
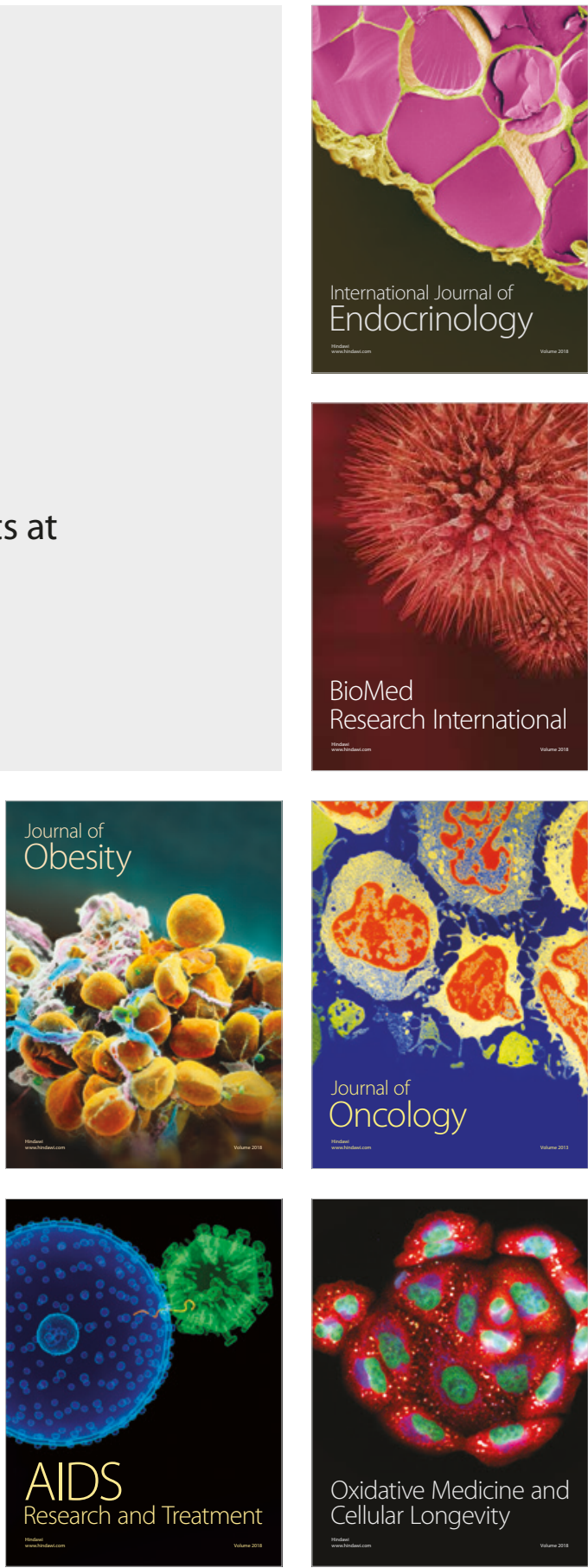